\title{
Low cigarette smoking prevalence in peri-urban Peru: results from a population- based study of tobacco use by self-report and urine cotinine
}

\author{
Brooks W. Morgan ${ }^{1}$, Kathryn M. Leifheit ${ }^{2}$, Karina M. Romero ${ }^{1,3}$, Robert H. Gilman ${ }^{4}$, Antonio Bernabe-Ortiz ${ }^{5}$,
} J. Jaime Miranda ${ }^{5}$, Harold I. Feldman ${ }^{6}$, John J. Lima', William Checkley ${ }^{1,4^{*}}$ and CRONICAS Cohort Study

\begin{abstract}
Background: A recent study found lower self-reported prevalence of tobacco smoking in a peri-urban area of Lima, Peru than previously reported in urban samples. These regions encompass substantial proportions of Peru's population - ones at greater risk of disease due to reduced healthcare access - but have been less often studied. We validate low smoking prevalence with urine cotinine and characterize chronic disease and lung function outcomes between non-, occasional, and daily smokers.

Methods: Data are from the CRONICAS Cohort Study, a population-based longitudinal study in four low-resource Peruvian settings, which began in 2010. Of a baseline cohort of 2978 adults, we prospectively followed 2583 (87\%) to determine prevalence of chronic illness.

Results: In a baseline sub-sample of 382 participants, median adjusted cotinine was $0.0 \mathrm{mcg} / \mathrm{mg}$ (IQR 0-0) for both self-reported non-smokers and occasional smokers compared to $172.3 \mathrm{mcg} / \mathrm{mg}$ (IQR 0-709.2) for daily smokers. Creatinine-adjusted cotinine validated daily smoking prevalence of $4.7 \%$ at a cutoff of $100 \mathrm{mcg} / \mathrm{mg}$. Kappa statistic for daily smoking and creatinine- adjusted cotinine $\geq 100 \mathrm{mcg} / \mathrm{mg}$ was 0.65 ( $95 \% \mathrm{Cl} 0.47,0.83$ ), indicating substantial agreement. At baseline, we found 3.3\% daily and $8.9 \%$ occasional smoking by self-report for the full cohort. Followup indicated little difference in chronic disease prevalence between groups. Daily smokers trended toward having a greater decline in FVC $(-1 \% ; 95 \% \mathrm{Cl}-2.9,0.8)$ and $\mathrm{FEV}_{1}(-1.3 \% ; 95 \% \mathrm{Cl}-3.2,0.6)$ over 40 months when compared to non-smokers, whereas the decline in lung function for occasional smokers was similar compared to non-smokers $(-0.2 \% \mathrm{FVC} ; 95 \% \mathrm{Cl}-1.5,1.0)$ and $\left(0 \% \mathrm{FEV}_{1} ; 95 \% \mathrm{Cl}-1.3,1.3\right)$.

Conclusions: Our data places Peru within a previously-described pattern of smoking found in much of Latin America, favoring occasional over daily smoking and low cigarette consumption. We determine that there are not significant differences between smoking groups concerning chronic disease outcomes. We favor distinguishing between daily and occasional smokers in order to accurately characterize these low-use populations.
\end{abstract}

Keywords: Tobacco, Smoking, Cotinine, Epidemiology

\footnotetext{
* Correspondence: wcheckl1@jhmi.edu

'Division of Pulmonary and Critical Care, School of Medicine, Johns Hopkins

University, 1830 E. Monument St, Baltimore, Maryland 21205, USA

${ }^{4}$ Program in Global Disease Epidemiology and Control, Department of

International Health, Bloomberg School of Public Health, Johns Hopkins

University, 615 N. Wolfe St, Baltimore, Maryland 21205, USA

Full list of author information is available at the end of the article
} 


\section{Background}

While tobacco smoking has declined dramatically in high-income countries, data suggests that it may be increasing in low- and middle-income countries (LMICs). This rise in smoking stands to accelerate countries' epidemiologic transitions, contributing to increasing rates of chronic disease morbidity and mortality [1, 2]. In these countries, accurate tobacco use data is essential for public health practitioners designing and implementing interventions to curb smoking and prevent chronic disease.

This work focuses on Peru as a case study. Peru is an LMIC showing early signs of increasing chronic disease, but an uncertain smoking landscape. Earlier studies that have attempted to estimate the prevalence of smoking in Peru have largely focused on urban areas, overlooking peri-urban shantytowns. The CARMELA study reported that the prevalence of current tobacco use - roughly, anyone who reported current daily or occasional inhaled tobacco use among those aged 25-64 years in urban Lima, Peru was $26.6 \%$ in 2005 [3]. The same year, the Center for Information and Education for the Prevention of Drug Abuse in Peru reported a $27.7 \%$ prevalence of all smoking and a $7.7 \%$ prevalence of daily smoking among those aged 12-64 years, also in urban Lima [4]. Meanwhile, our group estimated in a 2012 study that smoking prevalence may be substantially lower in peri-urban Lima, with a prevalence estimate of $16 \%$ for cigarette smoking among adults $\geq 40$ years old [5]. Importantly, only $2 \%$ of the sample were daily smokers with the balance reporting occasional smoking [5]. This finding, if true, has important public health implications for Peru. Given the increasing proportion of Peruvians residing in peri-urban zones, high-quality surveillance must be directed to these areas to derive estimates of chronic disease prevalence and risk.

Our first objective was to describe the tobaccousing population of peri-urban Peru by validating our low self-reported finding smoking prevalence with urine cotinine. Cotinine, the primary metabolite of nicotine, is a reliable [6] and valid [7, 8] biomarker that has been long used as a surrogate for tobacco smoke exposure in the previous $48 \mathrm{~h}$ [9-22]. We compared the prevalence of smoking by self-report with that based on a laboratory analysis of urine cotinine in a population-based sample of 382 adults from low-income peri-urban Lima and semi-urban Tumbes, Peru. Our second objective was to characterize the chronic disease burden in Peru, especially related to smoking status. To accomplish this, we compared chronic disease diagnoses, respiratory symptoms, biomarkers, and lung function scores over a 40-month follow up period between self-reported daily, occasional, and non-smokers over four separate field sites. For this analysis, we utilized our full cohort of 2978 adult participants.

\section{Methods \\ Study design and setting}

We utilized self-report and biomarker data collected at baseline in a random subsample of participants in the CRONICAS cohort, a prospective longitudinal study on cardiovascular disease, hypertension, diabetes, and lung function for which data collection began in September 2010 [23]. Recruitment sites were chosen to represent a cross-section of lowincome populations in Peru. These areas represent a large percentage of Peru's population and have access to fewer health resources; however, they are less often studied as they are not as accessible as urban populations [5]. Pampas de San Juan de Miraflores is a physically diverse, peri-urban community $25 \mathrm{~km}$ south of Lima's city center, and home to a large population of Andean immigrants which, studies have shown, suffer worsening cardiovascular risk profiles with urbanization similar to lifelong urban residents [24]. It represents a somewhat urbanized location at sea level with high ambient air pollution and low use of biomass fuels. Tumbes, on Peru's northern coast, is a mix of rural areas and growing urban sections. It is much less densely populated than the Lima site and represents a semi-urban location at sea level with low ambient air pollution and high biomass fuel use. Puno, in southeastern Peru, is home to two recruitment sites of 500 participants each, one rural and one urban. They are both at high altitude and feature low ambient air pollution; however, biomass fuel use, while rare in the urban site, is prevalent in the rural site.

\section{Participants, recruitment, and ethics}

Individuals were randomly selected from census data to form simple age- and sex-stratified cohorts of around 1000 participants per site. Study personnel visited the households of selected individuals to invite them to participate, ascertain oral consent (due to high rates of illiteracy), and perform baseline data collection. A random sub-sample of participants from Lima and Tumbes was invited to participate in ancillary studies (Puno was not included due to financial constraints). Inclusion criteria included age $\geq 35$ years and permanent residency of the area. Exclusion criteria included pregnancy, physical or mental disability (sufficient to impede implementation of the study protocol), and active pulmonary tuberculosis. The study protocol was reviewed and approved by the Institutional Review Boards of Johns Hopkins 
University in Baltimore, USA, and A.B. PRISMA and Universidad Peruana Cayetano Heredia in Lima, Peru.

\section{Data collection}

Data collection is described in detail elsewhere [23]. Briefly, baseline data collected during the recruitment visit included demographic, socioeconomic, and lifestyle risk factors (including smoking status); biomass exposure; and cardiovascular and respiratory symptoms, and was modified from WHO's STEP questionnaire for non-communicable disease and the Global Adult Tobacco Survey (GATS) [25, 26]. During the initial visit, appointments were made for a clinical evaluation. At the clinic, lung function was ascertained with a portable spirometer (Easy-On-PC, ndd, Zurich, Switzerland) both pre- and post-administration of salbutamol. Blood and urine were collected by a trained technician. The date of collection of biological samples ranged from 22 days before survey to 228 days afterward. Whole blood and plasma were collected in ethylenediaminetetraacetic acid (EDTA) containing tubes and sodium fluoride/ EDTA tubes, respectively, while urine was collected in $15 \mathrm{~mL}$ containers. Samples were stored at $4-8{ }^{\circ} \mathrm{C}$ for two weeks before being moved to a storage facility where the urine was separated into four $1.5 \mathrm{~mL}$ vials. Samples were then kept at $-20{ }^{\circ} \mathrm{C}$ until laboratory analysis. Our biological samples were all analyzed in a single laboratory. Assay quality was validated against external standards and internal duplicate assays and were monitored by BioRad (http:// www.bio-rad.com). Methods for the measurement of plasma glucose, serum insulin, hemoglobin A1c, total cholesterol, and HDL cholesterol are outlined in the parent sub-study protocol [27]. Urine creatinine was measured via modified kinetic Jaffé method. Urine cotinine was analyzed via gas chromatography-mass spectrometry [28]. The limit for detection was $0.16 \mathrm{ng} / \mathrm{mL}$. We present urine cotinine both unadjusted and standardized by level of urine creatinine (cotinine/creatinine ratio).

\section{Definitions}

Self-reported smoking was defined by the answer to the question, "Do you currently smoke cigarettes daily, occasionally, or not at all?" Current smoking was defined as a response of "Occasionally" ( $<1$ cigarette/day) or "Daily" (1+ cigarettes/day) while daily (active) smoking was defined as only those who responded "Daily." Based on previous research, adjusted urine cotinine was categorized into "none" (<10 mcg/mg), "low" (10-100 mcg/mg), and "high" $(\geq 100 \mathrm{mcg} / \mathrm{mg}$ ), which were used as references for our classifications of non-smoking, occasional/passive smoking, and daily (active) smoking, respectively [20, 29-33].

Fasting glucose, insulin, HbA1c, HDL, LDL, total cholesterol, and triglycerides were taken from blood samples. Diabetes mellitus was defined as self-reported physician diagnosis, use of anti-diabetic medications, or fasting plasma glucose $\geq 126 \mathrm{mg} / \mathrm{dL}$ [34]. Hypertension was defined as self-reported physician diagnosis, systolic blood pressure (SBP) $\geq 140 \mathrm{mmHg}$, diastolic blood pressure $(\mathrm{DBP}) \geq 90 \mathrm{mmHg}$, or receipt of anti-hypertensive therapy [35].

Insulin resistance was assessed using the homeostasis model assessment (HOMA-IR) by Matthews et al. [36]. The Framingham risk score (FRS) was calculated from the National Cholesterol Education Program Adult Treatment Panel III algorithm, which is based on cardiovascular risk factors, including age, sex, total cholesterol, HDL-cholesterol, systolic BP and smoking status [37]. Socioeconomic status was assessed using a wealth index based upon occupation, assets, and household income and facilities [38]. Body mass index (BMI) was calculated as weight $(\mathrm{kg})$ divided by height $(\mathrm{m})$ squared.

\section{Biostatistical methods}

To validate the prevalence of active smokers in periurban areas, prevalence estimates are reported as means with 95\% confidence intervals. Differences between recruitment sites were examined using Chi-square tests for categorical variables and Wilcoxon rank-sum tests or Student's t-tests for continuous variables. Agreement between self-reported smoking and adjusted cotinine categories were assessed with Fleiss' kappa statistic [39]. To characterize smoking populations, multivariable regressions were performed to assess the relationship between self-reported smoking status at baseline and health outcomes over follow-up. Continuous variables were analyzed with generalized linear mixed effects longitudinal models for change in means while logistic random effects models were used for binary variables. For all outcomes, the relevant chronic disease diagnosis, symptom, or biomarker was modeled as the dependent variable with smoking status as the independent predictor. To isolate the effects of smoking status, models included age, sex, site, and wealth index as covariates. Only those with complete follow-up were included in analyses. All analyses were conducted in STATA version 13 (StataCorp, College Station, Texas, USA).

\section{Results \\ Participant characteristics}

A total of 404 agreed to participate in the subsample, of which $50.2 \%$ were male with a mean age of 54.9 years old. Twenty-two were excluded from analysis for missing urine cotinine values. Overall, there were 2978 adult participants in the CRONICAS cohort with complete baseline data for analysis and 382 in a baseline subset of participants with urine cotinine values. Neither sex nor age differed between sites, though smoking did (Table 1). The cotinine subsample did not significantly vary from the balance of the 
Table 1 Demographic characteristics of recruitment sites and p-value for difference between sites, CRONICAS Study, Peru, 2010

\begin{tabular}{|c|c|c|c|c|c|}
\hline & Lima & Tumbes & Urban Puno & Rural Puno & $p$-value \\
\hline$n(\%)$ & $1004(33.7)$ & $966(32.4)$ & $503(16.9)$ & $506(17.0)$ & \\
\hline Age, median (IQR) & $54.7(45.4-64.1)$ & $54.7(44.7-64.6)$ & $54.8(44.9-64.4)$ & $54.8(45.1-63.9)$ & 0.82 \\
\hline Male, $n(\%)$ & $492(49.0)$ & $483(50.0)$ & $249(49.5)$ & $239(47.4)$ & 0.82 \\
\hline Daily use of biomass fuels, $n$ (\%) & $60(6.0)$ & $221(23.4)$ & $25(4.8)$ & $483(96.6)$ & $<0.001$ \\
\hline Education in years, $n(\%)$ & & & & & $<0.001$ \\
\hline Primary or Less & $424(42.2)$ & $524(54.3)$ & $72(14.3)$ & $318(62.9)$ & \\
\hline Secondary & $403(40.1)$ & $296(30.7)$ & $139(27.6)$ & $158(31.2)$ & \\
\hline Higher than Secondary & $177(17.6)$ & $145(15.0)$ & $292(58.1)$ & $30(5.9)$ & \\
\hline Wealth Index, $n$ (\%) & & & & & $<0.001$ \\
\hline Low & $121(12.1)$ & $311(32.3)$ & $120(23.9)$ & $356(70.4)$ & \\
\hline Medium & $366(36.5)$ & $393(40.9)$ & $129(25.7)$ & $136(26.9)$ & \\
\hline High & $517(51.5)$ & $258(26.8)$ & $254(50.5)$ & $14(2.8)$ & \\
\hline Smoking, $n(\%)$ & & & & & $<0.001$ \\
\hline Non-smoking & $855(85.2)$ & $843(87.4)$ & $447(88.9)$ & $469(92.7)$ & \\
\hline Occasional & $116(11.6)$ & $68(7.1)$ & $45(9.0)$ & $6(7.1)$ & \\
\hline Daily & $33(3.3)$ & $54(5.6)$ & $11(2.2)$ & $1(0.2)$ & \\
\hline Pack-years (ever smokers), median (IQR) & $0.1(0.0-0.8)$ & $0.5(0.1-4.6)$ & $0.1(0.0-1.2)$ & $0.1(0.0-0.3)$ & $<0.001$ \\
\hline
\end{tabular}

Bold indicates significance at $p=0.05$. Differences estimated by t-tests, Wilcoxon rank-sum, or Chi-squared tests

parent sample (Lima and Tumbes) in any measure (Additional file 1: Table S1).

A total of 2583 participants $(86.7 \%)$ remained in the study through 40-month follow up. The balance of 395 (13.3\%) was lost to follow up, twenty-three of whom were deceased. Most notably, participants from urban and rural Puno were more likely to be lost to follow up than those from Lima or Tumbes (Additional file 1: Table S2).

Among our full cohort at baseline, prevalence of current smoking was about $16.5 \%$ for those aged 35-54 years. This fell to $10 \%$ among those aged $55-64$ years and 5.5\% for those aged $\geq 65$ years (Additional file 1: Table S3). Men were three to seven times more likely to be current or daily smokers than women, with variations by age and site. Daily smokers comprised 99 of the 364 self-reported current smokers (27.2\%). Occasional smokers consumed a mean of 0.8 cigarettes per day while daily smokers consumed a mean of 4.3 cigarettes per day. Among occasional smokers, men consumed more cigarettes, but among daily smokers, males and females consumed the same. The highest mean number of cigarettes smoked per day by all current smokers was in Tumbes (2.2), followed by urban Puno (1.8), Lima (1.7), and rural Puno (0.2).

\section{Cotinine and self-reported smoking}

Sixty-one percent of participants had biological samples obtained within one month of survey administration. Twenty-six of our 382 sub-sample participants (6.8\%) had a urine cotinine level above zero. Among these, the median cotinine-creatinine ratio was $207.8 \mathrm{mcg} / \mathrm{mg}$ (IQR 119.4-496.1). Median adjusted cotinine was $0.0 \mathrm{mcg} / \mathrm{mg}$ (IQR 0-0) for both self-reported non-smokers and occasional smokers in our sample, compared to $172.3 \mathrm{mcg} / \mathrm{mg}$ (IQR 0-709.2) for daily smokers. Mean adjusted cotinine was $6.0,26.0$, and $354.4 \mathrm{mcg} / \mathrm{mg}$, for each group, respectively (Fig. 1). The difference in mean adjusted cotinine levels between occasional and non-smoking groups was not significant $(p=0.79)$, while cotinine levels in daily smokers were higher than in both occasional smokers and non-smokers $(p<0.001$, respectively). In our sub-sample, high adjusted cotinine validated daily smoking $(-0.8 \%$ difference, $p=0.62$; Table 2 ). The sensitivity, specificity, positive predictive value, and negative predictive value of selfreported daily smoking as compared to the gold standard of high cotinine in our sample were: $61.9 \%, 98.6 \%, 72.2 \%$, and $97.8 \%$, respectively. The length of time between interview and urine sample did not affect the validity of selfreported daily smoking (Additional file 1: Table S4). The kappa statistic for agreement in classification between the three levels of self-report and the three levels of urine cotinine was 0.40 (95\% CI 0.31, 0.45), indicating moderate agreement. Kappa for self-reported daily smokers and creatinine- adjusted cotinine (as dichotomous categories) was 0.65 (95\% CI 0.47, 0.83), indicating substantial agreement.

\section{Characterization of smokers}

Prevalence of reported symptoms, disease diagnoses, group means of continuous biomarkers, and lung testing scores by reported smoking classification for 


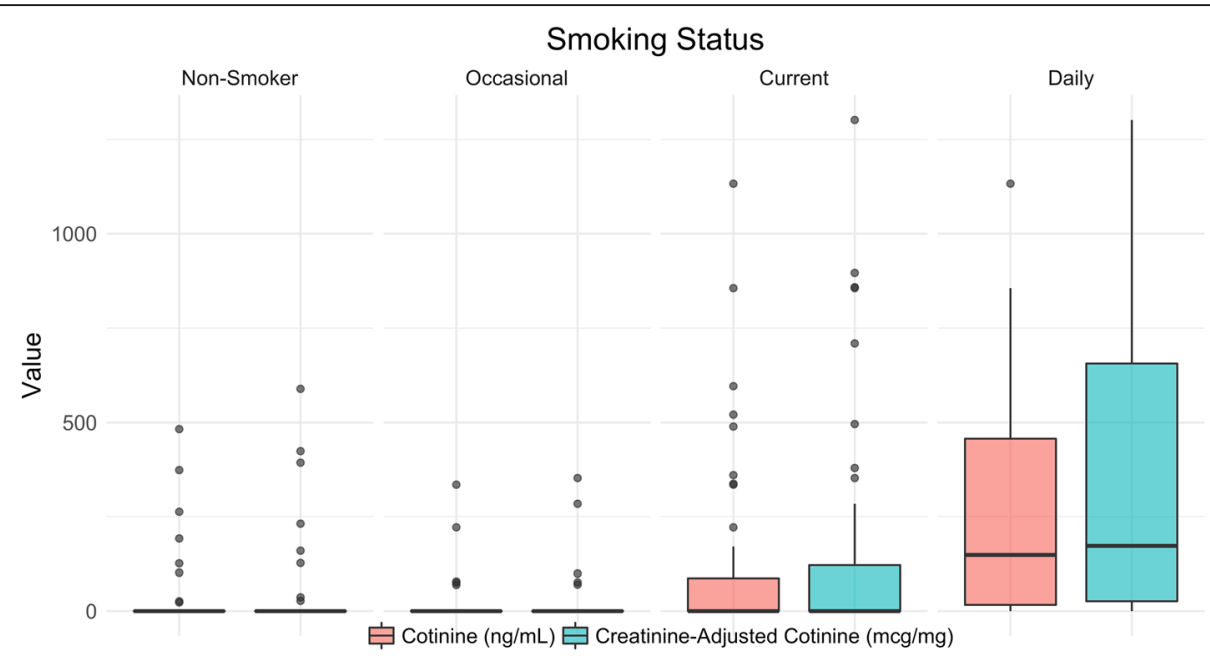

Fig. 1. Comparison of urine cotinine and adjusted cotinine values between smoking classifications: non-, occasional, current, and daily smokers.

baseline and 40-month follow up can be found in Table 3 and Additional file 1: Table S5. The reported odds ratios and differences in mean represent the occasional and daily smoking groups relative to nonsmokers. Additionally, self-reported occasional smokers in our sample had a mean lifetime smoking history of 1.27 pack-years compared to 1.12 packyears among non-smokers (37\% of whom were past smokers at study baseline) $(p=0.68)$. Self-reported daily smokers had a mean smoking history of 7.45 pack-years $(p<0.001$ vs. occasional and nonsmokers), which was comparable to the 9.50 pack years' history reported by past regular smokers $(p=0.26)$.

We modeled the change in lung function between baseline and follow up. Controlling for age, sex, site, and wealth index, daily smokers trended toward having a greater decline in FVC $(-1 \%$; $95 \% \mathrm{CI}-2.9,0.8)$ and $\mathrm{FEV}_{1}$ $(-1.3 \%$; $95 \%$ CI $-3.2,0.6)$ over 40 months when compared to non-smokers, whereas the decline in lung function was similar between occasional smokers and non- smokers $(-0.2 \%$ FVC; $95 \% \mathrm{CI}-1.5,1.0)$ and $\left(0 \% \mathrm{FEV}_{1}\right.$; $95 \%$ CI -1.3, 1.3).

Daily smokers trended toward an increase in BMI $(+1.10 \%$; $95 \%$ CI $-0.09,2.29)$ compared to occasional smokers $(+0.18 \%$; $95 \%$ CI $-0.61,0.97)$ against non-smokers.

Occasional smokers experienced an adjusted IRR for diabetes of 0.94 over follow up compared to non-smokers $(95 \%$ CI $0.48,1.84)$ while the IRR for daily smokers was 1.46 (95\% CI 0.63, 3.37). The IRR for hypertension for occasional smokers was $0.99(95 \%$ CI $0.62,1.56)$ and $0.73(95 \%$ CI $0.34,1.57$ ) for daily smokers.

\section{Discussion}

Systematic surveillance of tobacco use is an essential step in the formation of programs to reduce smokingrelated mortality, especially for those who joined the WHO's Framework Convention on Tobacco Control, which obliges signatory nations, including Peru, to implement policy changes to reduce tobacco use [26]. In our primary analysis, based on urine cotinine, we validate a lower prevalence of smoking in low-income

Table 2 Comparison of smoking prevalence (\%; 95\% confidence interval) by ascertainment method and site, CRONICAS Study, Peru, 2010

\begin{tabular}{|c|c|c|c|}
\hline Occasional smoking & $\begin{array}{l}\text { Lima } \\
(n=195)\end{array}$ & $\begin{array}{l}\text { Tumbes } \\
(n=187)\end{array}$ & $\begin{array}{l}\text { Total } \\
(n=382)\end{array}$ \\
\hline Self-Report & $10.3(6.0,14.5)$ & $7.5(3.7,11.3)$ & $8.9(6.1,11.8)$ \\
\hline Creatinine-Adjusted Cotinine (10-100 mcg/mg) & $0.5(-0.5,1.5)$ & $2.1(0.1,4.2)$ & $1.3(0.2,2.4)$ \\
\hline Difference by method & $9.7(5.4,14.1)$ & $5.3(1.0,9.7)$ & $7.6(4.5,10.7)$ \\
\hline Daily smoking & $\begin{array}{l}\text { Lima } \\
(n=195)\end{array}$ & $\begin{array}{l}\text { Tumbes } \\
(n=187)\end{array}$ & $\begin{array}{l}\text { Total } \\
(n=382)\end{array}$ \\
\hline Self-Report & $3.1(0.7,5.5)$ & $6.4(2.9,9.9)$ & $4.7(2.6,6.8)$ \\
\hline Creatinine-Adjusted Cotinine ( $\geq 100 \mathrm{mcg} / \mathrm{mg})$ & $2.1(0.1,4.0)$ & $9.1(5.0,13.2)$ & $5.5(3.2,7.8)$ \\
\hline Difference by method & $1.0(-2.1,4.2)$ & $-2.7(-8.1,2.7)$ & $-0.8(-3.9,2.3)$ \\
\hline
\end{tabular}

Bold indicates significance at $p=0.05$. Differences estimated by t-tests 
Table 3 Prevalence and means of chronic disease indicators at baseline and 40 month follow up, CRONICAS Study, multiple sites in Peru, 2010

\begin{tabular}{|c|c|c|c|c|c|c|}
\hline Outcome (Prevalence) & $N$ & Smoking Category & Baseline & Second Follow-Up & Adj. Odds Ratio ${ }^{a}$ & $p$-value \\
\hline \multirow[t]{3}{*}{ Hypertension, \% } & \multirow[t]{3}{*}{2583} & Non-Smoking & 27.2 & 32.2 & - & - \\
\hline & & Occasional & 19.3 & 24.0 & 0.86 & 0.75 \\
\hline & & Daily & 31.9 & 29.7 & 1.46 & 0.60 \\
\hline \multirow[t]{3}{*}{ Diabetes, \% } & \multirow[t]{3}{*}{2581} & Non-Smoking & 5.4 & 7.8 & - & - \\
\hline & & Occasional & 3.9 & 6.0 & 0.82 & 0.78 \\
\hline & & Daily & 3.3 & 8.8 & 1.31 & 0.73 \\
\hline \multirow[t]{3}{*}{ Stroke, \% } & \multirow[t]{3}{*}{2583} & Non-Smoking & 0.4 & 0.5 & - & - \\
\hline & & Occasional & 0.4 & 0.4 & 1.76 & 0.78 \\
\hline & & Daily & 1.1 & 1.1 & 5.62 & 0.44 \\
\hline \multirow[t]{3}{*}{ Cardiovascular Disease, \% } & \multirow[t]{3}{*}{2583} & Non-Smoking & 5.0 & 7.3 & - & - \\
\hline & & Occasional & 4.3 & 5.2 & 1.44 & 0.58 \\
\hline & & Daily & 8.8 & 13.2 & 10.24 & 0.001 \\
\hline \multirow[t]{3}{*}{ Overweight, \% } & \multirow[t]{3}{*}{2541} & Non-Smoking & 73.6 & 75.0 & - & - \\
\hline & & Occasional & 74.6 & 77.6 & 1.08 & 0.90 \\
\hline & & Daily & 64.8 & 71.4 & 0.23 & 0.09 \\
\hline \multirow[t]{3}{*}{ Obese, \% } & \multirow[t]{3}{*}{2541} & Non-Smoking & 29.3 & 30.1 & - & - \\
\hline & & Occasional & 24.1 & 25.9 & 0.30 & 0.14 \\
\hline & & Daily & 20.9 & 24.2 & 0.09 & 0.035 \\
\hline Outcome (Mean) & $N$ & Smoking Category & Baseline & Second Follow-Up & Adj. Difference in Mean ${ }^{a}$ & $p$-value \\
\hline \multirow[t]{3}{*}{ Systolic Blood Pressure (mmHg) } & \multirow[t]{3}{*}{2543} & Non-Smoking & 116.8 & 119.2 & - & - \\
\hline & & Occasional & 118.2 & 120.1 & 2.02 & 0.06 \\
\hline & & Daily & 121.2 & 123.2 & 0.98 & 0.54 \\
\hline \multirow[t]{3}{*}{ Body Mass Index $\left(\mathrm{kg} / \mathrm{m}^{2}\right)$} & \multirow[t]{3}{*}{2541} & Non-Smoking & 27.9 & 28.1 & - & - \\
\hline & & Occasional & 27.5 & 27.9 & -0.06 & 0.86 \\
\hline & & Daily & 27.0 & 27.5 & -0.74 & 0.11 \\
\hline \multirow[t]{3}{*}{$\mathrm{HDL}(\mathrm{mg} / \mathrm{dL})$} & \multirow[t]{3}{*}{2411} & Non-Smoking & 41.2 & 45.7 & - & - \\
\hline & & Occasional & 41.3 & 44.5 & 1.95 & 0.013 \\
\hline & & Daily & 40.6 & 43.6 & 0.83 & 0.49 \\
\hline \multirow[t]{3}{*}{ LDL (mg/dL) } & \multirow[t]{3}{*}{2410} & Non-Smoking & 127.7 & 120.9 & - & - \\
\hline & & Occasional & 125.2 & 116.5 & -1.24 & 0.58 \\
\hline & & Daily & 125.8 & 118.7 & -1.46 & 0.67 \\
\hline \multirow[t]{3}{*}{ Total Cholesterol (mg/dL) } & \multirow[t]{3}{*}{2411} & Non-Smoking & 201.4 & 198.4 & - & - \\
\hline & & Occasional & 198.4 & 192.5 & -0.92 & 0.73 \\
\hline & & Daily & 196.2 & 194.4 & -2.88 & 0.47 \\
\hline \multirow[t]{3}{*}{ Triglycerides (mg/dL) } & \multirow[t]{3}{*}{2411} & Non-Smoking & 163.2 & 159.0 & - & - \\
\hline & & Occasional & 159.5 & 157.5 & -9.22 & 0.15 \\
\hline & & Daily & 148.9 & 160.5 & -12.52 & 0.19 \\
\hline HOMA-IR & 2410 & Non-Smoking & 4.6 & 5.4 & - & - \\
\hline & & Occasional & 5.3 & 5.4 & 0.86 & 0.007 \\
\hline & & Daily & 4.2 & 5.3 & -0.15 & 0.75 \\
\hline Framingham Score & 2376 & Non-Smoking & 10.8 & 11.4 & - & - \\
\hline & & Occasional & 12.8 & 11.1 & 3.26 & $<0.001$ \\
\hline & & Daily & 13.6 & 13.5 & 3.57 & $<0.001$ \\
\hline
\end{tabular}


Table 3 Prevalence and means of chronic disease indicators at baseline and 40 month follow up, CRONICAS Study, multiple sites in Peru, 2010 (Continued)

\begin{tabular}{|c|c|c|c|c|c|c|}
\hline \multirow{3}{*}{$\begin{array}{l}\text { Post-Bronchodilator Forced } \\
\text { Vital Capacity }(L)\end{array}$} & 2278 & Non-Smoking & 3.42 & 3.33 & - & - \\
\hline & & Occasional & 4.18 & 4.08 & 0.05 & 0.17 \\
\hline & & Daily & 3.82 & 3.77 & -0.07 & 0.21 \\
\hline \multirow{3}{*}{$\begin{array}{l}\text { Post-Bronchodilator Forced Expiratory } \\
\text { Volume in One Second }(\mathrm{L})\end{array}$} & 2278 & Non-Smoking & 2.74 & 2.66 & - & - \\
\hline & & Occasional & 3.33 & 3.24 & 0.02 & 0.47 \\
\hline & & Daily & 3.10 & 2.99 & -0.03 & 0.53 \\
\hline
\end{tabular}

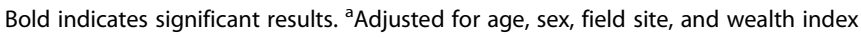

peri-urban areas than was reported in urban areas in previous large studies. It appears that Peru is part of a pattern seen in other Latin American countries, with the exception of the Southern Cone, that is characterized by smoking practices favoring occasional over daily smoking and fewer cigarettes consumed. The prevalence of self-reported smoking in our entire sample $(n=2978)$ was $3.3 \%$ daily, $8.9 \%$ occasional, and $12.2 \%$ current smokers. These findings are compatible with GATS data from Mexico [40], Costa Rica [41], and Panama [42]: all of which feature low smoking prevalence and daily smoking equal to or less than half of current smoking. This pattern of reduced tobacco use was previously noted by Tapia-Conyer et al., who found that daily smoking in Mexico decreased from $64 \%$ to $52 \%$ between 1988 and 1998 while among daily smokers, those who smoked five or fewer cigarettes/day increased from $49 \%$ to $74 \%$ [43]. Earlier, Samet et al. found that Hispanics in New Mexico tended to consume about half as many cigarettes as Whites, though prevalence of smoking and years smoked were similar [44]. This pattern contrasts with the Southern Cone countries, which have demonstrated higher smoking prevalence and frequency. Both the PLATINO and CARMELA studies report current smoking prevalence of nearly $40 \%$ in Chile and Argentina (WHO reports a drop to $29 \%$ in Argentina) while figures from GATS show a lower current smoking prevalence of $25 \%$ for Uruguay but notes that $80 \%$ of current smokers are also daily smokers [3, 45-47]. Menezes et al. note that only 2 of $1626(0.12 \%)$ current smokers in the PLATINO study were not daily smokers, contrasting remarkably with our findings in Peru [45].

Our self-reported smoking prevalence mirrors that published by Weygandt et al. but was substantially less than what the CARMELA study reported from Lima [3, 5]. In one comparison, we found $15.5 \%$ prevalence of current smoking in peri-urban Lima while CARMELA reported $26.6 \%$ prevalence for the 45-65 year age range [3]. For all ages in Lima, we found a current smoking prevalence of $14.8 \%$ and for all sites, $12.2 \%$. Additionally, CARMELA reported finding a mean of around 7 cigarettes consumed daily among currently smoking men and around 5 for women [3]. Our study found a mean of 1.8 cigarettes per day for men and 1.1 for women among current smokers in peri-urban Lima. However, it is important to note that these sets of estimates are not directly comparable: generally, CARMELA reported use of all inhaled tobacco in an urban sample of age 2565 years while we report cigarette use in adults aged $\geq 35$ years living in resource-poor settings [3]. One should also note that the relationship between nicotine intake and cigarettes smoked is not completely linear. Blackford et al. report that, in an international sample, participants tended to titrate smoking to their preferred nicotine level and not number of cigarettes smoked. Subsequently, those who smoked fewer than 20 cigarettes per day (99.5\% of our sample) consumed more nicotine per cigarette than those who smoked more [11].

In our secondary analysis, we attempted to characterize the smoking populations of low-income areas using longitudinal data. It is difficult to come to any conclusions about the long-term risk of chronic disease between groups, perhaps because the use of tobacco is so low, even among daily smokers. Only 3\% of our entire cohort reported a history of ten or more pack-years. Considering the general guidelines for lung cancer screening (loosely, $\geq 55$ years old and $\geq 30$ pack-years smoking), only $0.75 \%$ of our sample qualified [48-51]. Furthermore, there was no difference between mean pack-years for the occasional and non-smoking groups, indicating that the occasionally smoking group had a similar history to the then non-smokers.

Considering this, the relationships between lung function, obesity, and smoking status are of note. Unadjusted means show a greater loss of functional volume (FVC) and ability to exhale $\left(\mathrm{FEV}_{1}\right)$ for daily smokers compared to occasional and non-smokers and the gap was made more apparent by linear regression with age, sex, site, and 
wealth index, although the difference was not statistically significant. The same pattern was found when observing changes in BMI, with daily smokers experiencing a greater percentage rise in BMI than occasional or non-smokers. That pattern was also exacerbated in linear modeling though, again, it was not significant. No association was found with smoking status and change in systolic or diastolic blood pressures. This indicates that, even with relatively low levels of smoking, daily smokers in this sample may have a worsening risk profile for chronic disease than occasional or non-smokers. However, taking into account the rest of our data, the groups may not be different in a clinical way, which presents opportunities for the Peruvian government to intervene and prevent the public health situation from getting worse.

As an observation, multi-center surveys of smoking prevalence such as PLATINO did not distinguish between current and daily smoking, while those using the GATS protocol, such as CARMELA and our group, did [3, 5, 45]. Under the usual definition of current smoking - a small lifetime history and any reported smoking within a month or more - no value is given to the frequency of cigarette smoking, which, as shown by our sample, may be very low. The definition of active smoking from the PLATINO study would have included all of our self-reported daily smokers and $82 \%$ of our low-use occasional smokers, inappropriately characterizing our sample. As Weygandt et al. argue, including those who smoke as infrequently as they do in our sample represents an over-estimation of the actual active smoking prevalence in a population [5].

Strengths of this study include high-quality data collection methods and surveillance of disease outcomes, nested within a well-designed populationbased study, and standardized laboratory methods for measuring biomarkers. Limitations of this study include the small sample of daily smokers, which limited statistical power in attempts to characterize the group, and the larger number of participants lost to follow up in the Puno field sites, which may have skewed our health outcomes results. Additionally, the varying time between interview and biological sample question could change our associations but, since people in our sample rarely changed smoking status (our main exposure), we don't anticipate that the lags had any noticeable effect.

\section{Conclusions}

In summary, we used creatinine-adjusted urine cotinine to validate observed low prevalence of self-reported active smokers and low overall frequency of smoking in lowincome areas of Lima and Tumbes, Peru. This places Peru within an emerging pattern of low prevalence and frequency of smoking, favoring occasional smoking, seen in other Latin American countries except for those in the Southern Cone. As Peru is party to WHO's FCTC as of 2004, it is imperative that national policymakers have access to accurate epidemiological data on tobacco smoking in order to properly implement the MPOWER program.

In investigating longitudinal health outcomes data, we did not observe significant differences between groups of self-reported smokers, perhaps due to low levels of smoking across the population. However, even with low cigarette consumption, patterns can be seen that favor worsening lung function and BMI over time for daily smokers compared to occasional and non-smokers.

As a final observation, we recommend the use of the Global Adult Tobacco Survey protocol - which distinguishes between daily and current smoking - for tobacco use surveillance in future epidemiological studies. This would be especially useful in characterizing regions such as Peru, where the sole use of current smoking as an indicator overestimates the real prevalence of active smoking.

\section{Additional file}

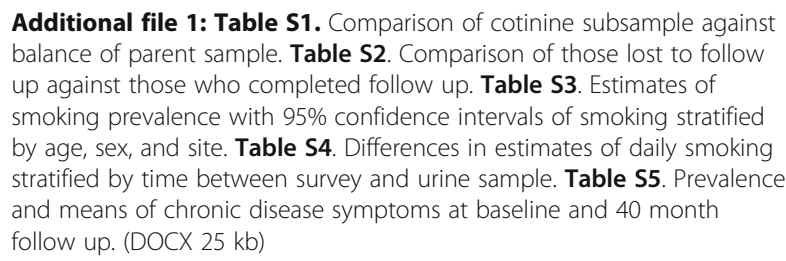

\section{Abbreviations}

BMl: body mass index; EDTA: ethylenediaminetetraacetic acid; FEV $V_{1}$ forced expiratory volume in one second; FRS: Framingham risk score; FVC: forced vital capacity; GATS: global adult tobacco survey; HOMA-IR: the homeostasis model assessment of insulin resistance; IQR: interquartile range; LMIC: Iow and middle income countries; WHO: World health organization

\section{Acknowledgements}

We would like to thank Prof. Jonathan Samet (University of Southern California) for his expert advice on reporting of results and messaging of this manuscript.

\section{Funding}

This work was supported in by the United States National Heart, Lung And Blood Institute, National Institutes of Health, Department of Health and Human Services contract HHSN268200900033C. William Checkley was further supported by a Pathway to Independence Award (R00HL096955) from the National Heart, Lung and Blood Institute, National Institutes of Health.

\section{Availability of data and materials}

The datasets used and/or analysed during the current study are available from William Checkley, Antonio Bernabe-Ortiz, or J. Jaime Miranda on reasonable request.

\section{Authors' contributions}

$\mathrm{BM}$ and $\mathrm{KL}$ were involved in the analysis, literature review and drafted introduction, results, and discussion piece of the article. KR was involved in analysis and literature review. RG and $A B O$ were involved in study design, study conduct, and interpretation of data. JM and HF were involved in study design, study conduct, interpretation of data, and contributed to drafting manuscript. $J \mathrm{~L}$ was involved in analysis of cotinine and interpretation of data. 
WC was involved in study design, study conduct, interpretation of data, and has overall responsibility for analysis, interpretation, and discussion of findings.

\section{Ethics approval and consent to participate}

The study protocol was reviewed and approved by the Institutional Review Boards of Johns Hopkins University in Baltimore, USA, and A.B. PRISMA and Universidad Peruana Cayetano Heredia in Lima, Peru. Each participant gave consent to participate.

\section{Consent for publication}

Not Applicable.

\section{Competing interests}

The authors have no conflicts of interest to disclose.

\section{Author details}

'Division of Pulmonary and Critical Care, School of Medicine, Johns Hopkins University, 1830 E. Monument St, Baltimore, Maryland 21205, USA. ${ }^{2}$ Department of Epidemiology, Bloomberg School of Public Health, Johns Hopkins University, 615 N. Wolfe St, Baltimore, Maryland 21205, USA. ${ }^{3}$ Biomedical Research Unit, A.B. PRISMA, Carlos Gonzales 251, 15088 San Miguel, Peru. ${ }^{4}$ Program in Global Disease Epidemiology and Control, Department of International Health, Bloomberg School of Public Health, Johns Hopkins University, 615 N. Wolfe St, Baltimore, Maryland 21205, USA. ${ }^{5}$ CRONICAS Center of Excellence in Chronic Diseases, Universidad Peruana Cayetano Heredia, 31 Av. Honorio Delgado 430, 15102 Lima, Peru.

${ }^{6}$ Department of Biostatistics and Epidemiology, Perelman School of Medicine at the University of Pennsylvania, 3400 Civic Center Blvd, Philadelphia, Pennsylvania 19104, USA. ${ }^{7}$ Center for Pharmacogenomics and Translational Research, Nemours Children Clinic, 14785 Old St. Augustine Rd, Jacksonville, Florida 32258, USA.

Received: 4 January 2017 Accepted: 12 July 2017

Published online: 21 July 2017

\section{References}

1. World Health Organization. WHO report on the global tobacco epidemic, 2011: warning about the dangers of tobacco. In Geneva: World Health Organization; 2011.

2. Yach D, Hawkes C, Gould CL, Hofman KJ. The global burden of chronic diseases: overcoming impediments to prevention and control. JAMA. 2004; 291(21):2616-22.

3. Champagne BM, Sebrie EM, Schargrodsky H, Pramparo P, Boissonnet C, Wilson E. Tobacco smoking in seven Latin American cities: the CARMELA study. Tob Control. 2010;19(6):457-62.

4. Castro de la Mata R, Zavaleta Martinez-Vargas A. Epidemiología de drogas en la población urbana peruana 2005: encuesta de hogares. In: Lima, Centro de Información y Educación para la Prevención del Abuso de Drogas, 2006.

5. Weygandt PL, Vidal-Cardenas E, Gilman RH, Avila-Tang E, Cabrera L, Checkley W. Epidemiology of tobacco use and dependence in adults in a poor peri-urban community in lima, Peru. BMC Pulm Med. 2012;12:9.

6. Abrams DB, Follick MJ, Biener L, Carey KB, Hitti J. Saliva cotinine as a measure of smoking status in field settings. Am J Public Health. 1987;77(7):846-8

7. Vartiainen E, Seppala T, Lillsunde P, Puska P. Validation of self reported smoking by serum cotinine measurement in a community-based study. J Epidemiol Community Health. 2002;56(3):167-70.

8. Haley NJ, Axelrad CM, Tilton KA. Validation of self-reported smoking behavior: biochemical analyses of cotinine and thiocyanate. Am J Public Health. 1983;73(10):1204-7.

9. Benowitz NL, Perez-Stable EJ, Herrera B, Jacob P 3rd. Slower metabolism and reduced intake of nicotine from cigarette smoking in ChineseAmericans. J Natl Cancer Inst. 2002:94(2):108-15.

10. Campuzano JC, Hernandez-Avila M, Jaakkola MS, Lazcano Ponce E, Kuri Morales P, Bautista P, Benowitz NL, Ceraso M, Blackford A, Samet JM. Determinants of salivary cotinine levels among current smokers in Mexico. Nicotine Tob Res. 2004;6(6):997-1008.

11. Blackford AL, Yang G, Hernandez-Avila M, Przewozniak K, Zatonski W, Figueiredo V, Avila-Tang E, Ma J, Benowitz NL, Samet JM. Cotinine concentration in smokers from different countries: relationship with amount smoked and cigarette type. Cancer Epidemiol Biomark Prev. 2006:15(10):1799-804.

12. Wagenknecht LE, Cutter GR, Haley NJ, Sidney S, Manolio TA, Hughes GH, Jacobs DR. Racial differences in serum cotinine levels among smokers in the coronary artery risk development in (young) adults study. Am J Public Health. 1990;80(9):1053-6.

13. Jarvis MJ, Russell MA, Benowitz NL, Feyerabend C. Elimination of cotinine from body fluids: implications for noninvasive measurement of tobacco smoke exposure. Am J Public Health. 1988;78(6):696-8.

14. Perez-Stable EJ, Herrera B, Jacob P 3rd, Benowitz NL. Nicotine metabolism and intake in black and white smokers. JAMA. 1998; 280(2):152-6.

15. Benowitz NL, Zevin S, Jacob P 3rd. Sources of variability in nicotine and cotinine levels with use of nicotine nasal spray, transdermal nicotine, and cigarette smoking. Br J Clin Pharmacol. 1997;43(3):259-67.

16. Sepkovic DW, Haley NJ. Biomedical applications of cotinine quantitation in smoking related research. Am J Public Health. 1985;75(6):663-5.

17. Benowitz NL. The use of biologic fluid samples in assessing tobacco smoke consumption. NIDA Res Monogr. 1983;48:6-26.

18. Benowitz NL, Kuyt F, Jacob P 3rd, Jones RT, Osman AL. Cotinine disposition and effects. Clin Pharmacol Ther. 1983;34(5):604-11.

19. Willers S, Skarping G, Dalene M, Skerfving S. Urinary cotinine in children and adults during and after semiexperimental exposure to environmental tobacco smoke. Arch Environ Health. 1995;50(2):130-8.

20. Haufroid V, Lison D. Urinary cotinine as a tobacco-smoke exposure index: a minireview. Int Arch Occup Environ Health. 1998;71(3):162-8.

21. Ahijevych KL, Tyndale RF, Dhatt RK, Weed HG, Browning KK. Factors influencing cotinine half-life during smoking abstinence in African American and Caucasian women. Nicotine Tob Res. 2002;4(4):423-31.

22. Kyerematen GA, Damiano MD, Dvorchik BH, Vesell ES. Smoking-induced changes in nicotine disposition: application of a new HPLC assay for nicotine and its metabolites. Clin Pharmacol Ther. 1982;32(6):769-80.

23. Miranda JJ, Bernabe-Ortiz A, Smeeth L, Gilman RH, Checkley W, Group CCS. Addressing geographical variation in the progression of non-communicable diseases in Peru: the CRONICAS cohort study protocol. BMJ Open. 2012; 2(1):e000610.

24. Miranda JJ, Gilman RH, Smeeth L. Differences in cardiovascular risk factors in rural, urban and rural-to-urban migrants in Peru. Heart. 2011;97(10):787-96.

25. World Health Organization. WHO STEPwise approach to surveillance (STEPS). STEPS manual. In Geneva: World Health Organization, 2017.

26. Palipudi KM, Morton J, Hsia J, Andes L, Asma S, Talley B, Caixeta RD, Fouad H, Khoury RN, Ramanandraibe N, et al. Methodology of the global adult tobacco survey - 2008-2010. Glob Health Promot. 2013;23(2):3-23.

27. Cusumano AM, Gonzalez Bedat MC, Garcia-Garcia G, Maury Fernandez S, Lugon JR, Poblete Badal H, Elgueta Miranda S, Gomez R, Cerdas Calderon M, Almaguer Lopez M, et al. Latin American dialysis and renal transplant registry: 2008 report (data 2006). Clin Nephrol. 2010;74(Suppl 1):S3-8.

28. James H, Tizabi Y, Taylor R. Rapid method for the simultaneous measurement of nicotine and cotinine in urine and serum by gas chromatography-mass spectrometry. J Chromatogr B Biomed Sci Appl. 1998;708(1-2):87-93.

29. Chilmonczyk BA, Knight GJ, Palomaki GE, Pulkkinen AJ, Williams J, Haddow JE. Environmental tobacco smoke exposure during infancy. Am J Public Health. 1990;80(10):1205-8.

30. Chilmonczyk BA, Salmun LM, Megathlin KN, Neveux LM, Palomaki GE, Knight GJ, Pulkkinen AJ, Haddow JE. Association between exposure to environmental tobacco smoke and exacerbations of asthma in children. N Engl J Med. 1993;328(23):1665-9.

31. Etzel RA. A review of the use of saliva cotinine as a marker of tobacco smoke exposure. Prev Med. 1990;19(2):190-7.

32. Jung S, Lee IS, Kim SB, Moon CS, Jung JY, Kang YA, Park MS, Kim YS, Kim SK, Chang J, et al. Urine Cotinine for assessing tobacco smoke exposure in Korean: analysis of the Korea National Health and nutrition examination survey (KNHANES). Tuberc Respir Dis (Seoul). 2012;73(4):210-8.

33. Fried PA, Perkins SL, Watkinson B, McCartney JS. Association between creatinine-adjusted and unadjusted urine cotinine values in children and the mother's report of exposure to environmental tobacco smoke. Clin Biochem. 1995;28(4):415-20.

34. Expert Committee on the D, Classification of Diabetes M. Report of the expert committee on the diagnosis and classification of diabetes mellitus. Diabetes Care. 2003;26(Suppl 1):S5-20. 
35. Chobanian AV, Bakris GL, Black HR, Cushman WC, Green LA, Izzo JL Jr, Jones DW, Materson BJ, Oparil S, Wright JT Jr, et al. The seventh report of the joint National Committee on prevention, detection, evaluation, and treatment of high blood pressure: the JNC 7 report. JAMA. 2003;289(19):2560-72

36. Matthews DR, Hosker JP, Rudenski AS, Naylor BA, Treacher DF, Turner RC. Homeostasis model assessment: insulin resistance and beta-cell function from fasting plasma glucose and insulin concentrations in man. Diabetologia. 1985;28(7):412-9.

37. National Cholesterol Education Program Expert Panel on Detection E, Treatment of High Blood Cholesterol in A. Third report of the National Cholesterol Education Program (NCEP) expert panel on detection, evaluation, and treatment of high blood cholesterol in adults (adult treatment panel III) final report. Circulation. 2002;106(25):3143-421.

38. Howe LD, Galobardes B, Matijasevich A, Gordon D, Johnston D, Onwujekwe O, Patel R, Webb EA, Lawlor DA, Hargreaves JR. Measuring socio-economic position for epidemiological studies in low- and middle-income countries: a methods of measurement in epidemiology paper. Int J Epidemiol. 2012;41(3):871-86.

39. Fleiss JL. Measuring nominal scale agreement among many raters. Psychol Bull. 1971;76(5):378-82

40. GATS: Global Adult Tobacco Survey, Fact Sheet, Mexico, 2009. [http://global. tobaccofreekids.org/files/pdfs/en/GATS_mexico_2009.pdf]. Last accessed: 15 July 2017.

41. GATS: Global Adult Tobacco Survey, Fact Sheet, Costa Rica, 2015. [http:// www.who.int/tobacco/surveillance/survey/gats/cri_factsheet_en.pdf?ua=1]. Last accessed: 15 July 2017.

42. GATS: Global Adult Tobacco Survey, Fact Sheet, Panama, 2013. [http://www. who.int/tobacco/surveillance/survey/gats/pan_factsheet2013.pdf?ua=1]. Last accessed: 15 July 2017.

43. Tapia-Conyer R, Kuri-Morales P, Hoy-Gutierrez MJ. Epidemiologic overview of smoking in Mexico. Salud Publica Mex. 2001;43(5):478-84.

44. Samet JM, Schrag SD, Howard CA, Key CR, Pathak DR. Respiratory disease in a New Mexico population sample of Hispanic and non-Hispanic whites. Am Rev Respir Dis. 1982;125(2):152-7.

45. Menezes AM, Lopez MV, Hallal PC, Muino A, Perez-Padilla R, Jardim JR, Valdivia G, Pertuze J, de Oca MM, Talamo C, et al. Prevalence of smoking and incidence of initiation in the Latin American adult population: the PLATINO study. BMC Public Health. 2009;9:151.

46. Prevalence of tobacco smoking [http://gamapserver.who.int/gho/ interactive_charts/tobacco/use/atlas.html]. Last accessed: 15 July 2017.

47. GATS: Global Adult Tobacco Survey, Fact Sheet, Uruguay, 2009.[http://www. who.int/tobacco/surveillance/fact_sheet_of_gats_uruguay_2010.pdf?ua=1]. Last accessed: 15 July 2017.

48. Detterbeck FC, Mazzone PJ, Naidich DP, Bach PB. Screening for lung cancer: diagnosis and management of lung cancer, 3rd ed: American College of Chest Physicians evidence-based clinical practice guidelines. Chest. 2013; 143(5 Suppl):e78S-92S.

49. Smith RA, Manassaram-Baptiste D, Brooks D, Doroshenk M, Fedewa S, Saslow D, Brawley OW, Wender R. Cancer screening in the United States, 2015: a review of current American cancer society guidelines and current issues in cancer screening. CA Cancer J Clin. 2015;65(1):30-54.

50. Bach PB, Mirkin JN, Oliver TK, Azzoli CG, Berry DA, Brawley OW, Byers T, Colditz GA, Gould MK, Jett JR, et al. Benefits and harms of $C T$ screening for lung cancer: a systematic review. JAMA. 2012;307(22):2418-29.

51. Jaklitsch MT, Jacobson FL, Austin JH, Field JK, Jett JR, Keshavjee S, MacMahon H, Mulshine JL, Munden RF, Salgia R, et al. The American Association for Thoracic Surgery guidelines for lung cancer screening using low-dose computed tomography scans for lung cancer survivors and other high-risk groups. J Thorac Cardiovasc Surg. 2012;144(1):33-8.

\section{Submit your next manuscript to BioMed Central and we will help you at every step:}

- We accept pre-submission inquiries

- Our selector tool helps you to find the most relevant journal

- We provide round the clock customer support

- Convenient online submission

- Thorough peer review

- Inclusion in PubMed and all major indexing services

- Maximum visibility for your research

Submit your manuscript at www.biomedcentral.com/submit

C) Biomed Central 